BOBO ZHAO, Ph.D. Student

(Corresponding author)

E-mail: bbzhao@bjtu.edu.cn

National Engineering Research Center of Rail

Transportation Operation and Control System

Beijing Jiaotong University

No.3 Shangyuancun, Xizhimenwai, Haidian District, Beijing,

100044, China

TAO TANG, Ph.D.

E-mail: ttang@ bjtu.edu.cn

BIN NING, Ph.D.

E-mail: bning@bjtu.edu.cn

State Key Laboratory of Rail Traffic Control and Safety

Beijing Jiaotong University

No.3 Shangyuancun, Xizhimenwai, Haidian District, Beijing,

100044, China

WEI ZHENG, Ph.D.

E-mail: wzheng1@bjtu.edu.cn

National Research Center of Railway Safety Assessment

Beijing Jiaotong University

No.3 Shangyuancun, Xizhimenwai, Haidian District, Beijing,

100044, China
Transport in Emergency Situations Original Scientific Paper

Submitted: Feb. 13, 2015

Accepted: Dec. 1, 2015

\title{
HYBRID DECISION-MAKING METHOD FOR EMERGENCY RESPONSE SYSTEM OF UNATTENDED TRAIN OPERATION METRO
}

\begin{abstract}
Suitable selection of the emergency alternatives is a critical issue in emergency response system of Unattended Train Operation (UTO) metro system of China. However, there is no available method for dispatcher group in Operating Control Center (OCC) to evaluate the decision under emergency situation. It was found that the emergency decision making in UTO metro system is relative with the preferences and the importance of multi-dispatcher in emergency. Regarding these factors, this paper presents a hybrid method to determinate the priority weights of emergency alternatives, which aggregates the preference matrix by constructing the emergency response task model based on the Weighted Ordered Weighted Averaging (WOWA) operator. This calculation approach derives the importance weights depending on the dispatcher emergency tasks and integrates it into the Ordered Weighted Averaging (OWA) operator weights based on a fuzzy membership relation. A case from train fire is given to demonstrate the feasibility and practicability of the proposed methods for Group Multi-Criteria Decision Making (GMCDM) in emergency management of UTO metro system. The innovation of this research is paving the way for a systematic emergency decision-making solution which connects the automatic metro emergency response system with the GMCDM theory.
\end{abstract}

\section{KEY WORDS}

decision making; emergency response system; Unattended Train Operation; metro; Ordered Weighted Averaging;

\section{INTRODUCTION}

Unattended Train Operation (UTO) refers to the automated metro system in which trains run fully automatically without any operating staff onboard [1]. For the advantages such as cost-effectiveness, high traffic frequency and flexibility, the UTO metro has a worldwide application spread as a global adoption trend.

The UTO metro system is composed of driverless CBTC systems, communication subsystems connecting passengers and the Operating Control Center (OCC), rolling stock with redundant major control systems and Integrated Supervisory and Control System (ISCS). To date, most studies on UTO metro have concentrated on how to guarantee safe and timely train operation, and the studies on decision making in the emergency response system have spread scarcely. The challenges of UTO metro operation are, without driver onboard, how the emergency response organization can find out the exceptional situation and restore the train back to normal operations. Several techniques have been developed to detect the emergency event, such as the fire and smoke alarm equipment, gap supervision device onboard, etc. Furthermore, the UTO metro system indicates that the OCC should ensure the detection and management of emergency situations [2]. Besides the emergency event itself, improper emergency responses and clearance of the contaminants can further contribute to the damage [3]. Therefore, 
the tasks of central dispatchers include dispatching emergency response personnel and equipment to the emergency site, coordinating the activities of all emergency response personnel and protecting passengers, personnel, and equipment at the emergency site.

Several researches have investigated the emergence response system in generic domain. Abrahamsson et al. [4] provided a better framework in which an emergency response system could functionalize during a specific operation and help to identify the potential events and/or circumstances, significantly affecting the performance of the emergency response system. Using task network mapping and analysis, Wang et al. [5] presented a method of improving the performance of emergency response system, taking the factor of time into consideration. There are also several technological approaches including database [6], Geographic Information System (GIS) [7, 8], mathematical models [9], and artificial intelligence such as Case-Based Reasoning $[10,11]$. However, all these studies did not emphasize that the human is the ultimate decision maker who has the responsibility of concentrating on the emergency accidents and minimizing the casualties and property losses. In addition, there have been some studies on human factor under emergency situation in UTO metro system. For example, Wang and Fang [12] presented a structured procedure to analyze the error behaviours of traffic dispatcher in emergency based on the human information processing theory and the modified task analysis framework. Karvonen et al. [13] analyzed the requirements of metro drivers to reveal what should be provided to compensate for the absence of a driver in UTO metro system. However, most papers studied human factor of single type position such as traffic dispatcher or driver, and the research in this paper will pay more attention to the group decision-making problem in OCC under UTO system emergency.

In case of any emergency in UTO metro, the tasks of the emergency response process are to organize the related agencies, raise and dispatch various resources, develop and carry out the emergency response plans immediately, with the goal of minimizing casualty and losses caused by disasters [14]. The crucial issue is how dispatchers can grasp the distinct and real information and make the proper decision. Decision making is a balance process within a number of criteria and opinions from different dispatchers, who have different knowledge about emergency alternatives [15]. Sometimes, these opinions from different dispatchers usually conflict with each other and therefore, the emergency alternative evaluation in UTO metro system is a typical group multi-criteria decision-making (GMCDM) problem. GMCDM aggregates the evaluations of alternatives to obtain the best solution for a problem from the information provided by some decision makers [16]. Several approaches have been developed to solve different types of real-world problems. One of the popular techniques uses the operator to aggregate each decision maker's information, and the operator weights are the key factors that affect the performance of alternatives selection.

All emergency situations should be understood and managed in OCC when UTO metro system is available. The necessary work is to adjust the organization in OCC to adapt to the new requirement. In lack of comprehensive experience concerned with organization studies from UTO metro system, we used the case of line YanFang in Beijing, which is under construction and will become the first UTO line regulated in automated operation in Beijing. Meanwhile, we investigated line 10 in Shanghai which has been designed as UTO system and found out that the characteristic of Beijing metro is different from Shanghai metro; then we attended the design and construction process of line YanFang and discussed the new changes in UTO metro, which should be understood in future operation.

The remainder of the paper is organized as follows: after the overview of dispatchers in OCC of UTO metro system, the problems are presented in Section 2; in Section 3, weighted ordered weighted averaging (WOWA) is introduced and a hybrid method integrating the dispatchers weights in UTO emergency response procedure and order weights into WOWA operator is specified to find out the priority weights of the alternatives. A case study is presented to demonstrate the proposed method in Section 4 and finally, some concluding remarks are discussed in Section 5.

\section{PRESENTATION OF PROBLEMS}

Since OCC is the organization which initiates the response to emergency situation, the dispatchers in OCC should be assigned to capture the characteristic of emergency situation and adopt appropriate response. There are six types of dispatchers in OCC on line YanFang, named by the traffic dispatcher, environment dispatcher, power dispatcher, passenger dispatcher, vehicle dispatcher and maintenance dispatcher. The responsibilities of these types of dispatchers are summarized in Table 1.

In conventional metro system, the driver has the responsibility to anticipate, observe, interpret, and react to emergency events in the surrounding situation [13]. From this view, taking care of the passengers and handling the exceptional events onboard should become the hidden tasks of the driver to execute and new responsibility should be assigned with new types of dispatchers in OCC. Therefore, the organization in OCC provides two new job positions for the dispatcher compared with the conventional dispatcher group. The new dispatchers are named by passenger dispatcher and vehicle dispatcher, which replace the driver to 
Table 1 - Detailed responsibilities of dispatchers in OCC

\begin{tabular}{||l|l||}
\hline \multicolumn{1}{|c|}{ Different dispatchers } & \multicolumn{1}{c||}{ Responsibilities } \\
\hline \hline Traffic dispatcher & $\begin{array}{l}\text { Managing and supervising the operation such as daily timetable, train service and train oper- } \\
\text { ation etc. }\end{array}$ \\
\hline Environment dispatcher & Managing and supervising electromechanical devices, water supply and drainage system. \\
\hline Power dispatcher & Managing and supervising third rail power supply devices. \\
\hline Passenger dispatcher & Supervising the passengers onboard and providing service to passengers under emergency. \\
\hline Vehicle dispatcher & $\begin{array}{l}\text { Supervising the status of equipment onboard and handling the exceptional situation onboard } \\
\text { remotely. }\end{array}$ \\
\hline Maintenance dispatcher & Receiving the failure and assigning the maintenance task. \\
\hline
\end{tabular}

provide emergency service for the passenger and handle exceptional situation onboard, respectively.

From the necessary changes in UTO metro system aforementioned, the arising new problems are summarized as follows:

1) Although the sophisticated techniques facilitate the possible application in UTO system of metro, the organization of metro faces the challenge of operation service. Without personnel onboard, any major failures or emergency events from the operated train are not easy to be handled quickly. Moreover, the passengers must be supplied with remote services by the OCC staff.

2) To solve the operation problem, the organization of OCC should be designed in a valid and effective way. The dispatchers should be assigned the responsibility of managing different subsystems including passenger, train, signalling system, station and infrastructure.

3) Considering the characteristics of emergency situation in UTO, the difficulty is that the uncertain factors of emergency situation, such as the location of emergency event, the scope of emergency event, and the passenger emotion under emergency, cannot be grasped by the dispatchers remotely in a short time.

4) When emergency event occurs, the dispatcher group should establish a chain of command assigning functions and responsibilities to appropriate personnel or equipment, maximizing the effectiveness of emergency response and minimizing the effect of emergency event.

Facing these challenges, a systematic view of emergency response task system for UTO system is presented, focusing on the importance of the decision maker with the factor including emergency event, goal and tasks; then we use ordered weights integrated with the importance weights of dispatchers to aggregate the information from different dispatchers. Proper priority of emergency decision could be obtained from this method, considering both the emergency response procedure and multi-dispatcher preference information.

\section{HYBRID METHOD FOR EMERGENCY ALTERNATIVES SELECTION}

\subsection{OWA operator}

The ordered weighted averaging (OWA) operator proposed by Yager [17] provided a unified framework for aggregation of decision making under uncertainty, in which preferential weights can be assigned to different decision criteria. Since OWA operator was introduced, it has been used widely in many fields of decision-making problems [18-21], and lots of extension studies about it have been introduced [22-26].

Definition 1: An OWA operator of dimension $n$ is a mapping OWA: $R^{n} \rightarrow R$ with an associated weighting vector $w=\left\{W_{1}, W_{2}, \ldots, w_{n},\right\}^{T}$ such that

$\sum_{i=0}^{n} W_{i}=1, w_{i} \in[0,1]$

and

OWA $=\left(a_{1}, a_{2}, \ldots, a_{n}\right)=\sum_{i=0}^{n} W_{i} b_{i}$,

where $b_{i}$ is the $i$-th largest of the $a_{i}$.

The OWA operator uses different decision criteria such as maximax (optimistic), maximin (pessimistic), etc., which express the decision maker's degree of optimism [27]. The OWA operator weights are measured by two important parameters, called dispersion (or entropy) and orness [17]. The dispersion can be interpreted as the entropy of the probability distribution and the orness measures the degree to which the aggregation is like an or operation, and can be viewed as a measure of optimism of a decision maker [28].

There were many methods of determining OWA operator weights for decision making in a valid way. Fulle' $r$ and Majlender [29] introduced a method of minimizing the variance of OWA operator weights under a given level of orness. Wang and Parkan [30] employed a linear programming (LP) to minimize the maximum disparity between two adjacent weights under a given level of orness. Wang et al. [31] presented an OWA operator weights named least squares deviation (LSD), minimizing the sum square of deviation between $w_{i}$ and $w_{i+1}$. Emrouznejad and Amin [32] provided an 
alternative disparity model to identify the OWA operator weights, extending the existing disparity approaches by minimizing the sum of the deviation between two distinct OWA weights. Furthermore, Amin and Emrouznejad [33] presented the set of multiple OWA weights in a parametric form which is useful to incorporate further information in the process of aggregation.

\subsection{WOWA operator}

The OWA operator provides the selection of various preferences of decision makers from the optimistic view to the pessimistic one [34]. However, it lacks consideration of importance weights through OWA operator. Actually, the weighted mean cannot be expressed in terms of the arithmetic mean of OWA aggregations [31]. To solve the problem, Torra [35] proposed the Weighted OWA (WOWA) aggregation which incorporated the important weighting into the OWA operator.

From the OWA operator, the WOWA operator takes two weighting vectors into consideration: the OWA operator weights $w$ and the importance weights $p$. The WOWA operator has been widely used in the fields of multi-criteria decision-making (MCDM) system and metadata aggregation problems [36, 37].

Definition 2: Let $\alpha=\left\{\alpha_{1}, \alpha_{2}, \ldots \alpha_{n}\right\}$ be a set of alternatives. Vectors $p=\left\{p_{1}, p_{2}, \ldots p_{n}\right\}^{T}$ and $w=\left\{w_{1}, w_{2}, \ldots w_{m}\right\}^{T}$ are two sets of weighting vectors, which satisfy:

\section{$\sum_{i=0}^{m} w_{i}=1, w_{i} \in[0,1], \sum_{i=0}^{n} p_{i}=1, p_{i} \in[0,1]$}

Definition 3: Let the vector $\left\{\alpha_{\sigma(1)}, \alpha_{\sigma(2)}, \ldots \alpha_{\sigma(n)}\right\}$ be a permutation of vector $\alpha=\left\{\alpha_{1}, \alpha_{2}, \ldots \alpha_{n}\right\}$, where $\alpha_{\sigma(1)} \geq \alpha_{\sigma(2)}$ $\geq \cdots \geq \alpha_{\sigma(n)}$

A WOWA operator of dimension $n$ is a mapping function: $R^{n} \rightarrow R$ with two weighting vectors of $p=\left\{p_{1}, p_{2}, \ldots p_{n}\right\}$ ${ }^{T}$ and $W=\left\{W_{1}, W_{2}, \ldots W_{m}\right\}^{T}$. The WOWA operator is defined as follows:

$\operatorname{WOWA}\left(\alpha_{1}, \alpha_{2}, \ldots \alpha_{n}\right)=\sum_{i=0}^{n} v_{i} \alpha_{\sigma(i)}$

with

$$
v_{i}=\omega^{*}\left(\sum_{j \leq i} p_{\sigma(j)}\right)-\omega^{*}\left(\sum_{j<i} p_{\sigma(j)}\right),
$$

where $\omega^{*}$ is an increasing function interpolating points $\left(1 / m, \sum_{j \leq i} w_{j}\right)$ together with the point (0.0). Function $\omega^{*}$ is required to be a straight line when the points can be interpolated in this way [24].

\subsection{Determining the importance weights of dispatcher}

Construction of the emergency response system with various actors and resources is an effective method to analyze and improve the performance of emergency [38]. Abrahamsson et al. [4] adopted different node shapes to map actors, tasks, resources and infrastructures, and the positive directions with four levels of strength were used to map dependencies in the emergency response system model. Using task network mapping and analysis, Wang et al. [5] took the time factor into consideration and presented a method of improving the performance of emergency response system, in which each node is used as a task involved in emergency response and a directed edge is employed to stand for the direct inherent dependency between two tasks.

The designation of command function chain is crucial to the capability of emergency response procedure. Here, an emergency response task model is proposed to cover three aspects: emergency dispatchers, tasks and goal. Considering the fact that aggregating dispatchers' preferences of emergency alternatives is the key issue of this study, the dependence relationship between different tasks is analyzed and the emergency response task model with four steps, as shown in Figure 1 is designed:

Step 1: Confirming the types and scopes of emergency.

Step 2: Setting the goals of emergency response.

Step 3: Identifying the dispatchers related to the emergency, represented by node of rectangle, which may include $m$ dispatchers $\left\{D_{1}, D_{2}, \ldots, D_{m}\right\}$.

Step 4: Selecting the tasks following the dispatchers, represented by node of rectangle, which may include $n$ tasks $\left\{t_{1}^{k}, t_{2}^{k}, \ldots, t_{n}^{k}\right\}$ of dispatcher $k$ with $1 \leq k$ $\leq \mathrm{m}$.

In UTO metro system, the dispatchers in OCC select the responding task content under the current

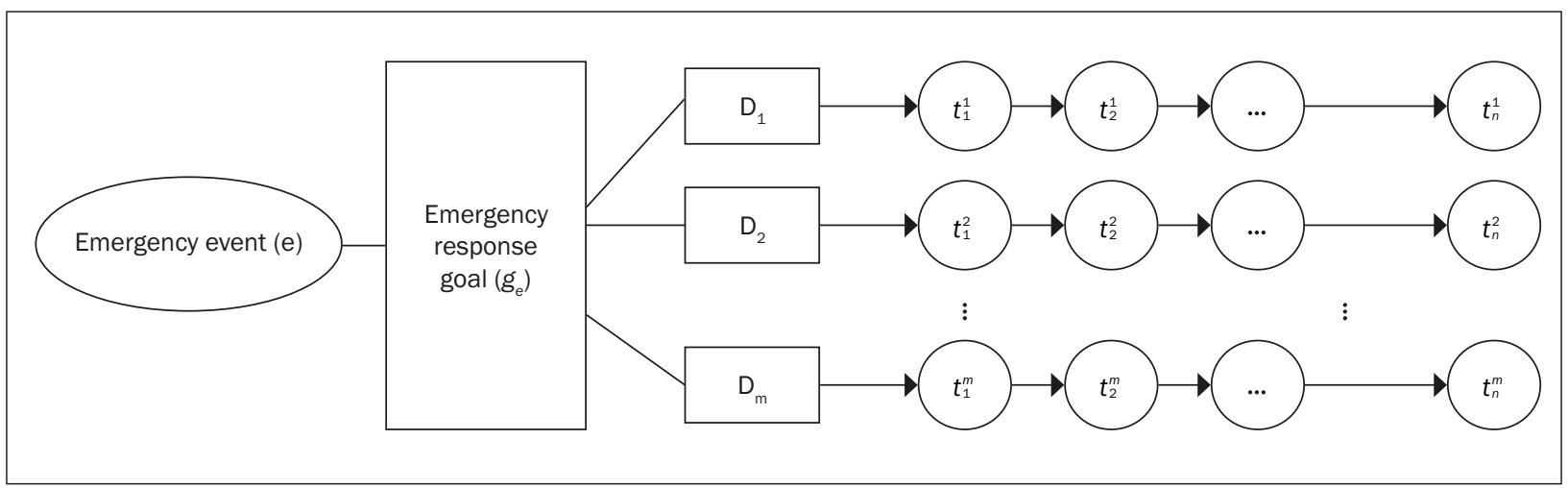

Figure 1 - Emergency response task model of dispatchers in OCC 
emergency event to meet the requirement arising from the response system. Hence, the relative importance weights of dispatchers may depend on their specific job responsibility. Another affecting factor is that the task content should vary timely with the urgent level of emergency response goal. Regarding these factors, revealing the dependence of dispatcher on the emergency goal under uncertain environment is crucial for the determination of the importance weights of dispatchers.

For each emergency, the important phase is to categorize dispatchers who are involved in the emergency response operation. Uhr and Johansson [39] used a snowballing process to provide a list of all the actors' activities during some parts of the emergency response operation. In this study, the involved dispatchers in several main emergency events in UTO metro system are presented from the detailed classification of responsibility of dispatchers in OCC, as shown in Table 2.

The response tasks of dispatchers have a close relationship with the types and severities of the emergency events in UTO metro system. To minimize the loss and the negative effect on system operational service, the dispatchers cooperate with each other to deal with the emergency event. From the goal of emergency, the tasks of dispatchers have different contents and numbers, which are relative with the dispatchers involved in the emergency response task system and the urgent level of emergency goal. For example, in case of a switch failure in front of the track, the traffic dispatcher needs to execute three tasks: lock the failure zone to avoid the entrance of a train, set the temporary train journey to maintain continuous revenue service, and adjust the running timetable to adapt to the failure event. Another case is the event of station fire, in which the traffic dispatcher will execute four tasks: setting the station skipped, commanding the station emergency response personnel to evacuate the passengers, setting the temporary train journey, and adjusting the running timetable.

Each dispatcher works in his own domain and derives the necessary tasks at the operational level. For the same emergency event, the operational steps are formed with the cooperation of different dispatchers. In case of person falling onto the platform track, the traffic dispatcher confirms to brake the train, the power dispatcher cuts off the electricity of the third rail, and the passenger dispatcher provides the ease service for passengers in the train to prevent the second damage. Hence, dispatchers in OCC have a close dependence on the current type of emergency event, and the goal of emergency response determines the contents of the tasks and the subsequent operations.

As aforementioned, in order to find the appropriate priority of decisions under uncertainty, the calculation approach is proposed to determine the Importance Weight (IW) of the dispatcher. $M=\{1,2, \ldots, m \mid m \in N\}$ is assumed as the set of dispatchers in OCC, and the tasks are derived from the emergency response task model.

The IW is defined by

$W_{(k, e)}=\frac{t s_{k}\left(g_{e}\right)}{\sum_{k=1}^{m} t s_{k}\left(g_{e}\right)}, 0 \leq I W_{(k, e)} \leq 1$,

where $\sum_{k=1}^{m} I W_{(k, e)}=1, g_{\mathrm{e}}$ is the emergency response goal under the emergency event, and $t s_{k}\left(g_{e}\right)$ is the number of tasks which the k-th dispatcher should execute to reach $g_{\mathrm{e}}$.

\subsection{Calculating alternative approach based on WOWA operator}

The OWA operator provided the selection of various preferences of decision makers from the optimistic view to the pessimistic one. However, it did not consider the importance weights through OWA operator which is important for evaluating emergency alternatives in UTO system, and the WOWA operator adopted the information of importance weights incorporated into the OWA operator.

Furthermore, it is observed that most of the LP disparity models produce regular weight distributions, which vary either in the form of exponential or in the form of arithmetical progression [40]. Although regular weight distributions make sense, there is no reason to believe that the OWA operator weights can vary regularly in emergency decision-making problem of UTO system. Besides, fuzziness and vagueness are

Table 2 - Involved dispatchers in several main emergency events in UTO metro system

\begin{tabular}{|l|c|c|c|c|c|c||}
\hline & $\begin{array}{c}\text { Traffic dis- } \\
\text { patcher }\end{array}$ & $\begin{array}{c}\text { Environment } \\
\text { dispatcher }\end{array}$ & $\begin{array}{c}\text { Power } \\
\text { dispatcher }\end{array}$ & $\begin{array}{c}\text { Passenger } \\
\text { dispatcher }\end{array}$ & $\begin{array}{c}\text { Vehicle } \\
\text { dispatcher }\end{array}$ & $\begin{array}{c}\text { Mainte- } \\
\text { nance } \\
\text { dispatcher }\end{array}$ \\
\hline \hline Emergency Brake Activation & $\sqrt{ }$ & & $\sqrt{ }$ & $\sqrt{ }$ & $\sqrt{ }$ \\
\hline Emergency Call Unit Activation & $\sqrt{ }$ & & $\sqrt{ }$ & $\sqrt{ }$ & $\sqrt{ }$ & \\
\hline Fire on Board/Platform & $\sqrt{ }$ & $\sqrt{ }$ & $\sqrt{ }$ & $\sqrt{ }$ & $\sqrt{ }$ \\
\hline Main Power Electric Failure & $\sqrt{ }$ & & $\sqrt{ }$ & $\sqrt{ }$ & $\sqrt{ }$ \\
\hline Accident & $\sqrt{ }$ & $\sqrt{ }$ & $\sqrt{ }$ & $\sqrt{ }$ & $\sqrt{ }$ \\
\hline Train blocked on the tracks & $\sqrt{ }$ & \multicolumn{5}{|}{} \\
\hline
\end{tabular}


the main characteristics of emergency decision-making problems in UTO system. For this reason, the fuzzy theory model rather than disparity model is more appropriate for determining the OWA operator weights. Hence, the WOWA operator integrated with fuzzy theory model [41] and importance weights is considered for emergency alternative evaluation of UTO metro system.

The importance weights evaluate the prominence of dispatcher as decision maker based on the proposed emergency response task model. However, the important weights of dispatcher are insufficient to select the emergency decision if several decision makers exist. Different decision makers have different preferences from the current goals and the preference aggregation of group decision makers is crucial for the performance of the emergency response task system.

The proposed approach is based on WOWA operator that assigns the importance of the dispatchers to the ordered weights to solve the problem of selecting emergency alternatives from multi-dispatcher of UTO metro. A systematic view is adopted to identify the tasks of different dispatchers under the emergency goal to decide the importance weights, and a fuzzy membership function is integrated to decide the OWA operator weights. There are six steps for this method:

Step 1: Construct the emergency response task model proposed in section 3.3.

Step 2: Let $w_{k}=\left\{w_{1}, w_{2}, \ldots w_{n}\right\}^{T}$ be the importance weights of dispatchers. The weights vector $w_{k}$ is calculated by (4):

$$
w_{k}=\frac{{ }_{t s_{k}\left(g_{e}\right)}}{\sum_{k=1}^{m} t s_{k}\left(g_{e}\right)}, 0 \leq w_{k} \leq 1
$$

Step 3: Let $W^{*}=\left\{w_{1}^{*}, w_{2}^{*}, \ldots w_{n}^{*}\right\}^{\top}$ be the OWA weights of preference relationship. The OWA weights vector $W_{q}^{*}$ is calculated by [41]:

$$
W_{q}^{*}=Q(q / n)-Q((q-1) / n)
$$

with $W_{q}^{*} \geq 0, \sum_{q=1}^{n} W_{q}^{*}=1$

where $\mathrm{Q}$ is a fuzzy membership function denoted by:

$$
Q(r)=\left\{\begin{array}{c}
0,1<\alpha \\
\frac{r-\alpha}{\beta-\alpha}, \alpha \leq r \leq \beta \\
1, r>\beta
\end{array}\right.
$$

with parameter $(\alpha, \beta)=(0.3,0.8)$, which indicates the fuzzy principle of majority.
Step 4: The aggregation weights $v_{i}$ are calculated by (3) based on the importance weights of dispatchers and OWA weights:

$v_{i}=\omega^{*}\left(\sum_{j \leq i} W_{\sigma(j)}^{*}\right)-\omega^{*}\left(\sum_{j<i} W_{\sigma(j)}^{*}\right)$,

where $\omega^{*}$ and $\omega_{\sigma(j)}^{*}$ are obtained by (3) from the section 3.2.

Step 5: $S^{*}=\left\{\boldsymbol{d}_{1}^{*}, \boldsymbol{d}_{2}^{*} \ldots, \boldsymbol{d}_{1 m}^{*}\right\}$ is assumed as a set of dispatchers and $P=\left\{P^{(1)}, P^{(2)}, \ldots, P^{(m)}\right\}_{n \times m}$ is assumed as the set of preference judgment vectors under the current emergency response goal, where $p^{(k)}=\left\{p_{1}^{(k)}, p_{2}^{(k)}, \ldots p_{n}^{(k)}\right\}^{T}$ with $1 \leq k \leq m$. The aggregation of preference judgment vectors $p_{i}^{*}$ is formulated with WOWA operator by:

$p_{i}^{*}=\sum_{l=0}^{m} v_{l} p_{l(i)}$

where $p_{l(i)}$ is $l$-th largest of $p_{i}^{(k)}$ with $1 \leq \mathrm{k} \leq \mathrm{m}$.

Step 6: The priority weights are obtained from the vector $p^{(*)}=\left\{p_{1}^{(*)}, p_{2}^{(*)}, \ldots p_{n}^{(*)}\right\}^{T}$. If there are multi-criteria, the priority weights should be considered as criteria weights. In this study, the weighted average method is used to get the ultimate priority weights vector.

\section{CASE STUDY}

The proposed method can be applied to the emergency decision making integrating all the opinions of dispatchers, in which the relationships between the preferences of dispatchers and the importance of dispatchers in emergency response task system are considered properly. A train fire when the train is running between the stations is taken as the case.

In case of fire detection, three criteria in the metro emergency situation are defined as: the safety of passengers (C1), the emergency response time of system (C2) and the performance of emergency recovery (C3). There are five emergency alternatives, represented by S1 to S5, as shown in Table 3.

It is assumed that $\mathrm{D}=$ \{Traffic dispatcher, Environment dispatcher, Passenger Dispatcher, Vehicle Dispatcher, Power dispatcher\} is the set of decision makers in OCC.

Step 1: The emergency response task model is constructed as Figure 2. The detailed tasks according to the responsibility of the dispatchers are summarized in Table 4. In order to calculate the importance weights

Table 3 - Emergency alternatives of train fire

\begin{tabular}{|c|l||}
\hline Number & \multicolumn{1}{c|}{ Alternatives } \\
\hline \hline S1 & $\begin{array}{l}\text { Allowing the train to continue its ride to the next safe place (e.g. next station) where the train can be } \\
\text { stopped and immobilized. }\end{array}$ \\
\hline S2 & $\begin{array}{l}\text { Holding the train between stations, and the train door is manually opened by passengers through the } \\
\text { broadcast from OCC. }\end{array}$ \\
\hline S3 & The passengers will be evacuated by the work staff between the stations. \\
\hline S4 & The passengers will be evacuated by the broadcast from OCC between the stations. \\
\hline S5 & The passengers will be evacuated by the station staff on the platform. \\
\hline
\end{tabular}




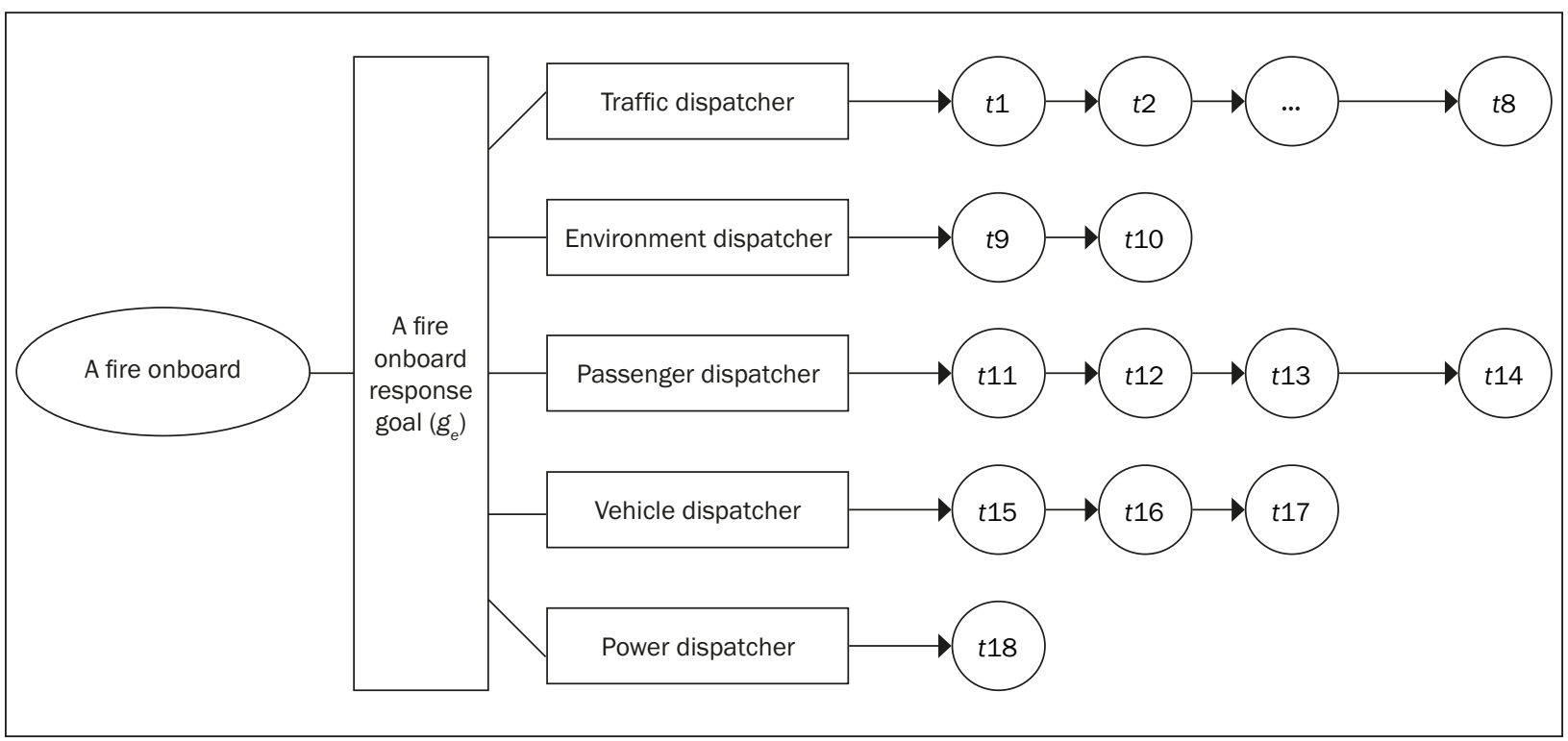

Figure 2 - Emergency response task model in case of train fire

Table 4 - Detailed tasks in case of train fire

\begin{tabular}{||c|l|c|l|c|l||}
\hline $\begin{array}{c}\text { Task } \\
\text { sequence }\end{array}$ & \multicolumn{1}{|c|}{ Task content } & $\begin{array}{c}\text { Task } \\
\text { sequence }\end{array}$ & \multicolumn{1}{|c|}{ Task content } & $\begin{array}{c}\text { Task } \\
\text { sequence }\end{array}$ & \multicolumn{1}{|c|}{ Task content } \\
\hline \hline $\mathrm{t} 1$ & $\begin{array}{l}\text { Holding train at next } \\
\text { station }\end{array}$ & $\mathrm{t} 7$ & $\begin{array}{l}\text { Communicating with } \\
\text { station work staff }\end{array}$ & $\mathrm{t} 13$ & $\begin{array}{l}\text { Releasing passenger } \\
\text { evacuation information }\end{array}$ \\
\hline $\mathrm{t} 2$ & Opening doors & $\mathrm{t} 8$ & $\begin{array}{l}\text { Establishing zone of } \\
\text { protection }\end{array}$ & $\mathrm{t} 14$ & $\begin{array}{l}\text { Monitoring passenger } \\
\text { evacuation process }\end{array}$ \\
\hline $\mathrm{t} 3$ & $\begin{array}{l}\text { Holding train between } \\
\text { stations }\end{array}$ & $\mathrm{t} 9$ & $\begin{array}{l}\text { Communicating with fire } \\
\text { departments }\end{array}$ & $\mathrm{t} 15$ & Opening platform doors \\
\hline $\mathrm{t} 4$ & $\begin{array}{l}\text { Making other trains emer- } \\
\text { gency stop remotely }\end{array}$ & $\mathrm{t} 10$ & $\begin{array}{l}\text { Releasing fire onboard } \\
\text { emergency plan }\end{array}$ & $\mathrm{t} 16$ & $\begin{array}{l}\text { Monitoring fire alarm } \\
\text { indicator }\end{array}$ \\
\hline $\mathrm{t} 5$ & $\begin{array}{l}\text { Communicating with pas- } \\
\text { senger dispatcher }\end{array}$ & $\mathrm{t} 11$ & Monitoring coach & $\mathrm{t} 17$ & $\begin{array}{l}\text { Communicating with } \\
\text { traffic dispatcher }\end{array}$ \\
\hline $\mathrm{t} 6$ & $\begin{array}{l}\text { Communication with envi- } \\
\text { ronment dispatcher }\end{array}$ & $\mathrm{t} 12$ & $\begin{array}{l}\text { Communication with } \\
\text { passengers }\end{array}$ & $\mathrm{t} 18$ & Cutting off third rail power \\
\hline
\end{tabular}

of each dispatcher when the emergency response model is constructed, we should calculate the number of the tasks belonging to the respective dispatcher. Hence, the remark of the task is just sequential such that we expect to have a whole overview of the tasks in each emergency case.

Step 2: The importance weights of dispatchers defined in set $D$ are calculated by (4): $w=\{0.44,0.11,0.22,0.17,0.06\}^{T}$.

Step 3: The preference vectors of different emergency alternatives under the criteria are presented in the following matrices, as shown from Table 5 to Table 7. The five involved dispatchers in this case: Traffic dispatcher, Environment dispatcher, Passenger Dispatcher, Vehicle Dispatcher, Power dispatcher, gives the preference data of emergency alternatives under three criteria: the safety of passengers (C1), the emergency response time of system (C2), and the perfor- mance of emergency recovery (C3). These tables are original data from dispatchers in UTO system.

The OWA operator weights of dispatcher are obtained by (5) and (6): $w^{*}=\{0,0.2,0.4,0.4,0\}^{\top}$.

Step 4: Based on the vector $w$ and $w^{\star}$, the aggregation weights can be calculated by (7): $v=\{0,0,0.14,0.38,0.48\}^{T}$.

Step 5: $p_{i j}^{*}$ denotes the aggregation value of dispatcher preference to emergency alternative i under criterion $\mathrm{j}$ and is calculated by (8) from the approach discussed. Hence, the preference judgment of different dispatchers under multi-criteria $p^{*}=\left\{p_{1}^{*}, p_{2}^{*}, p_{3}^{*}\right\}_{5 \times 3}$ is obtained in Table 8. The table demonstrates the aggregation matrix of the involved dispatchers' preferences under three criteria: the safety of passengers (C1), the emergency response time of the system (C2) and the performance of emergency recovery (C3).

Step 6: From the safety principle of automatic metro, the weights of criteria are calculated as $\{0.5,0.3,0.2\}$, 
B. Zhao, et al.: Hybrid Decision-making Method for Emergency Response System of Unattended Train Operation Metro

Table 5 - Preference matrix under the criteria of safety of passengers

\begin{tabular}{||c|c|c|c|c|c|c||}
\hline & Dispatcher & $\begin{array}{c}\text { Traffic } \\
\text { dispatcher }\end{array}$ & $\begin{array}{c}\text { Environment } \\
\text { dispatcher }\end{array}$ & $\begin{array}{c}\text { Passenger } \\
\text { dispatcher }\end{array}$ & $\begin{array}{c}\text { Vehicle dis- } \\
\text { patcher }\end{array}$ & $\begin{array}{c}\text { Power } \\
\text { dispatcher }\end{array}$ \\
\hline $\begin{array}{c}\text { Emergency } \\
\text { alternatives }\end{array}$ & & & & & \\
\hline \hline S1 & & 0.333 & 0.333 & 0.133 & 0.333 & 0.333 \\
\hline S2 & & 0.200 & 0.200 & 0.333 & 0.267 & 0.200 \\
\hline S3 & & 0.067 & 0.067 & 0.267 & 0.133 & 0.133 \\
\hline S4 & & 0.133 & 0.133 & 0.200 & 0.067 & 0.067 \\
\hline S5 & & 0.267 & 0.267 & 0.067 & 0.200 & 0.267 \\
\hline
\end{tabular}

Table 6 - Preference matrix under the criteria of emergency response time of system

\begin{tabular}{|c|c|c|c|c|c|c||}
\hline & Dispatcher & $\begin{array}{c}\text { Traffic } \\
\text { dispatcher }\end{array}$ & $\begin{array}{c}\text { Environment } \\
\text { dispatcher }\end{array}$ & $\begin{array}{c}\text { Passenger } \\
\text { dispatcher }\end{array}$ & $\begin{array}{c}\text { Vehicle dis- } \\
\text { patcher }\end{array}$ & $\begin{array}{c}\text { Power } \\
\text { dispatcher }\end{array}$ \\
\hline $\begin{array}{c}\text { Emergency } \\
\text { alternatives }\end{array}$ & & & & & & \\
\hline \hline S1 & & 0.133 & 0.333 & 0.133 & 0.333 & 0.333 \\
\hline S2 & & 0.333 & 0.200 & 0.333 & 0.267 & 0.200 \\
\hline S3 & & 0.200 & 0.067 & 0.200 & 0.133 & 0.133 \\
\hline S4 & & 0.267 & 0.133 & 0.267 & 0.067 & 0.067 \\
\hline S5 & 0.067 & 0.267 & 0.067 & 0.200 & 0.267 \\
\hline
\end{tabular}

Table 7 - Preference matrix under the criteria of performance of emergency recovery

\begin{tabular}{|c|c|c|c|c|c|c||}
\hline & Dispatcher & $\begin{array}{c}\text { Traffic } \\
\text { dispatcher }\end{array}$ & $\begin{array}{c}\text { Environment } \\
\text { dispatcher }\end{array}$ & $\begin{array}{c}\text { Passenger } \\
\text { dispatcher }\end{array}$ & $\begin{array}{c}\text { Vehicle dis- } \\
\text { patcher }\end{array}$ & $\begin{array}{c}\text { Power } \\
\text { dispatcher }\end{array}$ \\
\hline $\begin{array}{c}\text { Emergency } \\
\text { alternatives }\end{array}$ & & & & & \\
\hline S1 & & 0.333 & 0.333 & 0.133 & 0.333 & 0.333 \\
\hline S2 & & 0.200 & 0.200 & 0.333 & 0.200 & 0.200 \\
\hline S3 & & 0.067 & 0.067 & 0.200 & 0.067 & 0.067 \\
\hline S4 & & 0.133 & 0.133 & 0.267 & 0.133 & 0.133 \\
\hline S5 & 0.267 & 0.267 & 0.067 & 0.267 & 0.267 \\
\hline
\end{tabular}

Table 8 - Aggregation matrix under multi criteria

\begin{tabular}{||c|c|c|c|c||}
\hline & Dispatcher & C1 & C2 & C3 \\
\hline \hline Emergency alternatives & & & & \\
\hline S1 & & 0.333 & 0.333 & 0.333 \\
\hline S2 & & 0.289 & 0.329 & 0.263 \\
\hline S3 & & 0.178 & 0.142 & 0.131 \\
\hline S4 & & 0.165 & 0.248 & 0.197 \\
\hline S5 & & 0.258 & 0.258 & 0.267 \\
\hline
\end{tabular}

and after normalization, the priority weights are calculated as $p^{*}=\{0.2718,0.2417,0.1116,0.1628,0.2121\}^{\top}$, which means the sequence of the priority of emergency alternatives:

$\mathrm{s} 1 \succ \mathrm{s} 2 \succ \mathrm{s} 5 \succ \mathrm{s} 4 \succ \mathrm{s} 3$.

From the result, the emergency alternative S1, allowing the train to continue running to the next safe place, is the first priority selection. The result demon- strates that dispatchers in metro system always prefer to process train emergency response procedure and command entry of the emergency train into station in any emergency situations. The alternative S2 of holding the train between stations is the second .priority selection to decide how the fire train moves. After making a decision of the fire train, the alternatives of evacuating passengers should have proper priority 
decision, and S5, evacuated by the station staff on the platform is the third priority selection for the aforementioned principle. Alternative S4 of evacuating passengers by the broadcast from OCC between the stations is the fourth priority selection for the reason of time elapsed. Furthermore, it will cost some time if station staff goes into the guide way between stations, the fire may cause the second damage to passengers. Hence, alternative S3 of evacuating the passengers by the work staff between the stations is the last selection.

The result has been discussed and verified by the experienced dispatchers in Beijing metro. In summary, the result of the aggregation method of dispatcher's preferences applied on the case of a train fire during the operation process between the stations is consistent with the real emergency guidance in the situation of UTO system.

\section{CONCLUSION}

Evaluating and implementing emergency alternative effectively is critical to the UTO metro's safe operation and people's lives. The preferences of dispatcher group in OCC have a key impact on the performance of emergency response. To find out the optimized emergency solution, an appropriate decision making method for group decision-making support was proposed for dispatchers to adapt for the new UTO metro system of China.

In the proposed method, the preference weights of emergency alternatives are obtained by integrating the fuzzy membership relation of dispatchers' preferences as well as mapping the tasks of dispatchers in OCC into the emergency response task system to determine importance weights of dispatchers. The inter-relationship between dispatchers and their respective preferences is calculated through assigning the importance weights of dispatchers to the OWA operator weights. This method has been demonstrated and partially validated through a case study of train fire. The result of the case is such consistent with the real emergency guidance that the application of the method will decrease the work load of dispatchers in UTO system.

In this way, the method for choosing emergency measures under group multi-criteria provides the benchmarking framework for the training of dispatchers in UTO metro. The method could be adopted in an emergency training software, in which the dispatchers could carry out emergency exercises in several scenarios. The proposed method will give a score which evaluates the decision of dispatchers and improve the dispatcher's skill and experience. More, the method also could be used to support the optimal evaluation of emergency decision-making of dispatchers and compensate for the challenge in UTO metro system of China.
Further study will focus on the algorithm for the incomplete information of dispatcher's preference and the validation of emergency alternatives evaluation through agent-based pedestrian simulation model.

\section{ACKNOWLEDGEMENT}

This work was supported by the Fundamental Research Funds for the Central Universities (project number: 2016JBM006), Beijing Laboratory of Urban Rail Transit, and Beijing Key Laboratory of Urban Rail Transit Automation and Control.

赵波波, 通讯作者, 北京交通大学 轨道交通运行控 制系统国家工程研究中心。北京市海淀区西直门外 上园村3号。邮编: 100044. 邮箱: bbzhao@bjtu.edu. cn

唐涛, 北京交通大学 轨道交通控制与安全国家重 点实验室。北京市海淀区西直门外上园村3号。邮 编：100044. 邮箱: ttang@bjtu.edu.cn

宁滨, 北京交通大学轨道交通控制与安全国家重 点实验室。北京市海淀区西直门外上园村3号。邮 编：100044. 邮箱: bning@bjtu.edu.cn

郑伟, 北京交通大学 国家轨道交通安全评估研 究中心。北京市海淀区西直门外上园村 3 号。邮 编: 100044. 邮箱: wzheng1@bjtu.edu.cn

\section{地铁无人驾驶应急响应系统的混合决策方法}

摘要

应急决策的恰当选择是中国地铁无人驾驶系统中的 一个关键问题。目前, 没有一种可用的方法适用于 控制中心的OCC调度员应急决策评估。应急决策的选 择与调度员的决策偏好以及调度员重要性有着密切 关系。因此, 本文提出了一种针对地铁无人驾驶系 统应急决策优先级权重确定的混合方法, 该方法基 于WOWA算子聚集了应急响应任务模型下的调度员偏 好矩阵, 考虑了基于应急任务的调度员重要性权重 并通过一种模糊隶属关系将其集成于OWA算子。本 文通过列车火灾进行案例说明, 验证了论文中提出 的面对地铁无人驾驶系统下的应急多准则群决策方 法。本方法的创新之处在于地铁无人驾驶应急响应 系统与多准则群决策理论的有效结合。

\section{关键词}

决策; 应急响应系统; 无人列车驾驶; 地铁; 有序 加权平均算子;

\section{REFERENCES}

[1] UITP, 2011, Press kit Metro automation facts, figures and trends- a global bid for automation: UITP Observatory of Automated Metros confirms sustained growth rates for the coming years, 2011. Available from: http://www.uitp.org/sites/default/files/Metro\%20automation\%20-\%20facts\%20and\%20figures.pdf. 
[2] Draft EN 62290-2 Railway applications - Urban guided transport management and command/control systems, Part 2: Functional requirements specification, 2011. Available from: http://webstore.iec.ch/Webstore/webstore.nsf/Artnum_PK/49864.

[3] Fu T. Environmental emergency and typical cases [in Chinese]. Beijing: China Environmental Science Press, 2006. Available from: http://www.cesp.cn/list.asp?id $=210$

[4] Abrahamsson M, Hassel H, Tehler H. Towards a system-oriented framework for analysing and evaluating emergency response. J. Contingencies Crisis Manage. 2010 April;18 (2):14-25. Available from: http://onlinelibrary.wiley.com/doi/10.1111/j.14685973.2009.00601.x/abstract

[5] Wang D, Qi C, Wang H. Improving emergency response collaboration and resource allocation by task network mapping and analysis. Safety Science. 2014 Dec;70:918. Available from: http://www.sciencedirect.com/science/article/pii/S0925753514001106

[6] Scott $\AA$, Tysklind M, Fängmark I. Selection of a representative set of chemical accidents from a complex data matrix for the development of environment accident index. Journal of hazardous materials. 2002 Feb;91(1):63-80. Available from: http://www.sciencedirect.com/science/article/pii/ S0304389401003879

[7] Assaf H, Saadeh M. Assessing water quality management options in the Upper Litani Basin, Lebanon, using an integrated GIS-based decision support system. Environmental Modelling and Software. 2008 Oct-Nov;23(10-11):1327-1337. Available from: http://www.sciencedirect.com/science/article/pii/ S1364815208000479

[8] Didan K, Yitayew M. Prototype geographic information system for agricultural water quality management using cropSyst. Journal of Irrigation and Drainage Engineering. 2009 Jan;135(1):58-67. Available from: http://cedb.asce.org/cgi/WWWdisplay.cgi?169770

[9] Bianconi R, Galmarini S, Bellasio R. Web-based system for decision support in case of emergency: ensemble modeling of long-range atmospheric dispersion of radionuclides. Environmental Modelling and Software. 2004 April;19(4):401-411. Available from: http://www.sciencedirect.com/science/article/pii/ S1364815203001397

[10] Liao Z, Wang B, Xia X, Hannam PM. Environmental emergency decision support system based on Artificial Neural Network. Safety Science. 2012 Feb;50(1):150163. Available from: http://www.sciencedirect.com/ science/article/pii/S0925753511001615

[11] Mao X. CBR adaptation methodology for environmental emergency response system based on genetic algorithm [Master Thesis, in Chinese]. Shanghai: Tongji University; 2010. Available from: http://webpac.lib. tongji.edu.cn/opac/item.php?marc_no=0001992004

[12] Wang J, Fang W. A structured method for the traffic dispatcher error behavior analysis in metro accident investigation. Safety Science. 2014 Dec;70:339-347. Available from: http://www.researchgate.net/publication/264827394_A_structured_method_for_the_traffic_dispatcher_error_behavior_analysis_in_metro_accident_investigation
[13] Karvonen $\mathrm{H}$, Aaltonen I, Wahlström M, et al. Hidden roles of the train driver: A challenge for metro automation. Interacting with Computers. 2011 Aug;23(4):289298. Available from: http://www.sciencedirect.com/ science/article/pii/S0953543811000427

[14] Lindell MK, Prater C, Perry RW. Wiley pathways introduction to emergency management. John Wiley \& Sons; 2006. Available from: https://books.google.com.hk/ books?hl=zh-CN\&Ir=\&id=swNb7 bzjYilC\&oi=fnd\&p$g=P A 1 \& d q=$ Wiley+Pathways+Introduction+to+Emergency+Management\&ots $=$ Q_mAzJbPiF\&sig $=T J i K b-$ 4ZhTzRa5SIBHyrxvvOHLGI\#v=onepage \&q=Wiley $\% 20$ Pathways\%20Introduction\%20to\%20Emergency\%20 Management\&f=false

[15] Ju Y, Wang A. Emergency alternative evaluation under group decision makers: A method of incorporating DS/ AHP with extended TOPSIS. Expert Systems with Applications. 2012 Feb;39(1):1315-1323. Available from: http://www.sciencedirect.com/science/article/pii/ S0957417411011237

[16] Meng D, Pei Z. On weighted unbalanced linguistic aggregation operators in group decision making. Information Sciences. 2013 Feb;223:31-41. Available from: http://dl.acm.org/citation.cfm?id=2401275

[17] Yager RR. On ordered weighted averaging aggregation operators in multi-criteria decision making. IEEE Transactions on Systems, Man and Cybernetics. 1988 Jan;18(1):183-190. Available from: http://ieeexplore. ieee.org/xpl/articleDetails.jsp?arnumber $=87068$

[18] Emrouznejad A. MP-OWA: The most preferred OWA operator. Knowledge-Based Systems. 2008 Dec;21(8):847851. Available from: http://www.sciencedirect.com/ science/article/pii/S0950705108000919

[19] Zhou SM, Chiclana F, John RI, Garibaldi JM. Type1 OWA operators for aggregating uncertain information with uncertain weights induced by type2 linguistic quantifiers. Fuzzy Sets and Systems. 2008 July;159(24):3281-3296. Available from: http://citeseerx.ist.psu.edu/viewdoc/download?doi=10.1.1.192.9546\&rep=rep1\&type=pdf

[20] Liamazares B. Choosing OWA operator weights in the field of Social Choice. Information Sciences. $2007 \mathrm{Nov} ; 177(21): 4745-4756$. Available from: http://www.sciencedirect.com/science/article/pii/ S0020025507002459

[21] Merigó JM, Gil Lafuente AM. The generalized adequacy coefficient and its application in strategic decision making. Fuzzy Economic Review. 2008 April;13(2):17-36. Available from: http://dialnet.unirioja.es/servlet/articulo?codigo $=2882398$

[22] Merigó JM, Gil-Lafuente AM. New decision making techniques and their application in the selection of financial products. Information Sciences. 2010 Nov;180(11):2085-2094. Available from: http://www.sciencedirect.com/science/article/pii/ S0020025510000502

[23] Chen Y, Li K. An OWA-TOPSIS method for multiple criteria decision analysis. Expert Systems with Applications. 2011 May;38(5):5205-5211. Available from: http://www.sciencedirect.com/science/article/pii/ S0957417410011838

[24] Ogryczak W, Śliwiński T. On efficient WOWA optimization for decision support under risk. International Jour- 
nal of Approximate Reasoning, 2009 Jun;50(6):915928. Available from: http://www.sciencedirect.com/ science/article/pii/S0888613X09000425

[25] Yager RR. Weighted maximum entropy OWA aggregation with applications to decision making under risk. IEEE Transactions on Systems, Man and Cybernetics Part A. 2009 May;39(3):555-564. Available from: http://ieeexplore.ieee.org/xpl/articleDetails.jsp?arnumber $=4803772$

[26] Yager RR. Prioritized OWA aggregation. Fuzzy Optimization and Decision Making. 2009 Aug;8(3):245262. Available from: http://link.springer.com/article/10.1007\%2Fs10700-009-9063-4?LI=true

[27] Yager RR. On the cardinality index and attitudinal character of fuzzy measures. International Journal of General Systems. 2002 April;31(3):303-329. Available from: http://www.tandfonline.com/doi/ abs/10.1080/03081070290018047\#.VNxgTPmUeSo

[28] Wang YM, Luo Y, Liu X. Two new models for determining OWA operator weights. Computers \& Industrial Engineering. 2007 March;52(2):203-209. Available from: http://www.sciencedirect.com/science/article/ pii/S0360835206002075

[29] Fullér R, Majlender P. An analytic approach for obtaining maximal entropy OWA operator weights. Fuzzy Sets and Systems. 2001 Nov;124(1):53-57. Available from: http://www.sciencedirect.com/science/article/pii/ S0165011401000070

[30] Wang YM, Parkan C. A minimax disparity approach for obtaining OWA operator weights. Information Sciences. 2005 Sep;175(1):20-29. Available from: http:// dl.acm.org/citation.cfm?id=1103390

[31] Amin GR, Notes on properties of the OWA weights determination mode. Computers \& Industrial Engineering. 2007 May;52(4):533-538. Available from: http://www.sciencedirect.com/science/article/pii/ S0360835207000472

[32] Emrouznejad A, Amin GR. Improving minimax disparity model to determine the OWA operator weights. Information Sciences. 2010 Nov;180(8):1477-1485. Available from: http://www.sciencedirect.com/science/ article/pii/S0020025509005210

[33] Amin GR, Emrouznejad A. Parametric aggregation in ordered weighted averaging. International journal of approximate reasoning. 2011 Feb;52(6):819-827. Available from: http://www.sciencedirect.com/science/article/pii/S0888613X1100051X

[34] Grabisch M, Orlovski SA, Yager RR. Fuzzy aggregation of numerical preferences. Fuzzy sets in decision analysis, operations research and statistics. 1998 Jan;1:31-68. Available from: http://link.springer.com/ chapter/10.1007/978-1-4615-5645-9_2

[35] Torra V. The weighted OWA operator. International Journal of Intelligent Systems. 1997 Dec;12(2):153-166. Available from: http://onlinelibrary.wiley.com/doi/10.1002/(SICI)1098-111X (199702)12:2\%3C153::AID-INT3\%3E3.0.CO;2-P/abstract

[36] Valls A, Torra V. Using classification as an aggregation tool in MCDM. Fuzzy Sets and Systems. 2000 Oct;115(1):159-168. Available from: http://www. sciencedirect.com/science/article/pii/S016501 1499000299

[37] Nettleton D, Muñiz J. Processing and representation of meta-data for sleep apnea diagnosis with an artificial intelligence approach. International journal of medical informatics. 2001 Feb;63(1):77-89. Available from: http://www.iiia.csic.es/files/pdfs/nettleton_ijmi.pdf

[38] Uhr C, Johansson H, Fredholm L. Analysing emergency response systems. Journal of Contingencies and Crisis Management. 2008 May;16(2):80-90. Available from: http://onlinelibrary.wiley.com/doi/10.1111/j.14685973.2008.00536.x/abstract

[39] Uhr C, Johansson H. Mapping an emergency management network. International Journal of Emergency Management. 2007 Feb;4(1):104-118. Available from: http://gordion.casaccia.enea.it/Progetto-Reti/ cnip06/slides/Session6/Uhr.pdf

[40] Wang YM, Luo Y, Liu X. Two new models for determining OWA operator weights[J]. Computers \& Industrial Engineering. 2007 Jan;52(2):203-209. Available from: http://www.sciencedirect.com/science/article/pii/ S0360835206002075

[41] Jiang YP, Fan ZP. Decision theory and method based on judgement matrix. Science press; 2008 Dec. Available from: http://www.sciencep.com/s_single. php?id=16934 